\title{
Ruinas y legitimidad en Massinga. Formas de pensar el pasado entre ancianos empobrecidos del sur de Mozambique
}

\author{
Albert Farré
}

Recibido: 12 de marzo de 2016 / Aceptado: 25 de julio de 2016

Resumen. A partir del trabajo de campo etnográfico en el distrito de Massinga, en este artículo analizo la legitimidad de las autoridades tradicionales como un proceso de negociación que no puede desvincularse de la historia regional del África austral. Las transformaciones sociales producidas por el Estado colonial y la industria minera afectaron a las sociedades africanas. Los migrantes a las minas, excluidos de la modernidad en la que participaban, estaban a la vez dentro y fuera de dos procesos de reproducción social. Así, de entre los jóvenes proletarios de cada generación saldrían los futuros ancianos tradicionales. Esta posición ambigua se reflejaba en la construcción de casas cada vez más modernas, lo que, a su vez, contribuía a que cada nueva generación renovase la legitimidad de las instituciones tradicionales. Cuando los hombres perdieron la centralidad social que las minas les otorgaban, también perdieron la capacidad de renovar la legitimidad tradicional de sus instituciones.

Palabras clave: autoridad tradicional; Estado; migración labora; rito de paso; ruptura generacional.

\section{[en] Ruins and Legitimacy in Massinga. Ways of Thinking the Past among Impoverished Elders in Southern Mozambique}

\begin{abstract}
Drawing from ethnographic fieldwork in Massinga district, this article presents the building up of traditional authority's legitimacy as a process linked to southern Africa regional history. Both the colonial State and the mining industry transformed African societies. Rural migrants, despite being confined to the customary sphere, were in fact straddling two different systems of social reproduction, as for successful young proletarians would become respected traditional elders. Thanks to this ambiguous position, each generation of migrants was able to build new and fancy houses. By doing so, they also contributed to renewing the legitimacy of traditional institutions. Once the mines stopped the recruitment of Mozambican young miners, the usual way to renew legitimacy collapsed.
\end{abstract}

Keywords: traditional authority; State; labour migration; rite of passage; generation gap.

Sumario. 1.Democracia y legitimidad en Mozambique: Los partidos, la nación y la tradición.1.1 Salir de la burbuja urbana.1.2 Extirpar el colonialismo de la cabeza: la reeducación del régulo.1.3 La revolución ante la diversidad rural y las modernidades alternativas. 1.4 Ancianos que rememoran su pasado. 1.5 La migración como rito de paso y la reproducción social de las sociedades rurales. 1.6 La transición a la democracia y el auge de la recuperación de la tradición. 2.Formas de pensar el pasado y el self tras la ruptura colonial. 3.Las ruinas y la legitimidad en Massinga. 4. Referencias bibliográficas.

Cómo citar: Farré, A. (2016). Ruinas y legitimidad en Massinga. Formas de pensar el pasado entre ancianos empobrecidos del sur de Mozambique, en Revista de Antropología Social, 25(2), 361-387.

$1 \quad$ Universidad de Brasília (UnB)

fantura2@hotmail.com 
En este artículo me propongo abordar las formas de relacionarse con el pasado que coexisten en Mozambique, y su relación con los debates sobre la legitimidad tradicional antes y después de la independencia. Mi análisis se centra en el distrito de Massinga, situado en la provincia de Inhambane, y especialmente en un grupo de ancianos con el mantengo contacto desde el año 2006, cuando inicié allí mi trabajo de campo etnográfico. Estos ancianos han vivido la última fase del periodo colonial y la independencia de Mozambique, que tuvo lugar en 1975; el intento de revolución socialista y la larga guerra civil que se siguió; y finalmente la transición a la democracia iniciada tras los Acuerdos de Paz de 1992, que no han supuesto todavía la salida del poder del mismo partido que proclamó la independencia. Además, Inhambane forma parte de las tres provincias del sur de Mozambique que, durante el periodo colonial, fueron destinadas como reserva de mano de obra para las minas de oro surafricanas. Los cambios en el sector minero surafricano han ido siempre acompañando a los cambios geopolíticos en la región y, aunque menos visibles que estos últimos, a menudo han tenido un impacto importante en la vida de los mozambiqueños. Uno de los objetivos del artículo es mostrar hasta qué punto la memoria colectiva del sur de Mozambique está unida a la migración laboral a las minas.

La independencia de Mozambique supuso también la búsqueda de un relato sobre la historia de la nación mozambiqueña (Cahen, 2010; Borges Coelho, 2013, 2015). Desde la independencia se han sucedido dos grandes intentos de pensar el pasado nacional. La primera propuesta se empezó a gestar durante la lucha por la independencia, iniciada en 1964, cuando se planteaba la necesidad de una nueva identidad nacional mozambiqueña capaz de construir un estado independiente completamente diferente al estado colonial, pues sólo así — se aseguraba - los mozambiqueños conseguirían librarse definitivamente de todas las herencias coloniales (Cabaço, 2001). En este primer momento, pues, se postulaba la independencia como una ruptura radical con el pasado, y empezó a perfilarse la idea de un Homem Novo, un ciudadano de nuevo cuño que fuese capaz de afrontar el futuro sin ninguna de las desigualdades e injusticias heredadas del pasado. Los proponentes del Hombre Nuevo apostaban por un modelo de sociedad no sólo más igualitaria sino también más uniforme, pues consideraban la diversidad de lenguas y culturas como un lastre social del cual el colonialismo se había aprovechado para conseguir sus intereses.

La segunda propuesta reivindicaba la legitimidad de las autoridades tradicionales, y propició un debate especialmente intenso en Mozambique durante los años noventa, coincidiendo con la transición a la democracia (West y Kloeck-Johnason, 1999; Farré, 2006). En el contexto de la reforma del Estado hacia el pluralismo político, uno de los puntos clave era saber qué lugar correspondía a aquellas autoridades cuya existencia era previa al establecimiento del Estado colonial. Estas autoridades fueron calificadas de "tradicionales" precisamente para enfatizar sus vínculos con el pasado precolonial, y difuminar en lo posible las distorsiones sufridas durante el colonialismo. Este segundo debate surgió como alternativa al fracaso del Hombre Nuevo revolucionario y, de hecho, su propuesta se fundamentaba en la estrategia contraria: el pasado precolonial era el que proporcionaría las bases para construir un orden social coherente con las instituciones mozambiqueñas más antiguas y genuinas. Tras una década y media de debates de gran intensidad, esta propuesta también

2 Este artículo ha sido posible gracias al programa de investigación postdoctoral PNPD-CAPES del gobierno brasileño. 
decayó, y el interés por la recuperación de lo tradicional como tabla de salvación ante los retos del futuro acabó por diluirse.

En este artículo argumento que ninguno de los dos relatos se ha consolidado, en gran medida porque ambos se basaban en una idea errada, por demasiado estática, de la legitimidad y sus formas de reproducirse. Así, mi principal objetivo es relacionar el fracaso de ambas propuestas con los recuerdos de los ancianos de Massinga. Mi argumento es que a través del ejemplo de estos ancianos se puede entender mejor cómo en el pasado se fue actualizando la legitimidad en las zonas rurales del sur de Mozambique. Además, sus vidas también nos pueden ayudar a saber porqué ellos ya no pueden actualizar esa legitimidad.

El artículo se estructura en tres partes. La primera parte la dedico a contextualizar la vida de estos ancianos de Massinga, entrelazando la información sobre sus vidas con la historia de Mozambique. El hecho que uno de ellos pertenezca a una familia que ostentaba el cargo de "régulo" me ayudará a introducirme en la controvertida cuestión de las diversas legitimidades políticas en contextos postcoloniales (Massó Guijarro, 2007). Régulo es una palabra de origen colonial que los portugueses inicialmente usaban para designar a las autoridades africanas en general. Más tarde, con la Reforma Administrativa Ultramarina que acompañó el establecimiento del Estado Novo en Portugal (1933), régulo pasó a designar a aquellas autoridades africanas integradas en la red administrativa del Estado colonial. La carga de ambigüedad de la palabra régulo ha sido heredada por la nueva designación que entró en vigor ya en el periodo democrático: las autoridades comunitarias.

En la segunda parte, me propongo responder a la pregunta de por qué ninguno de los dos relatos sobre el pasado consiguieron convencer a estos ancianos. Para hacerlo recurriré a algunos conceptos elaborados por João de Pina Cabral (2000, 2006), tales como solidaridades primarias, preteridad, márgenes y hegemonía. Estos conceptos me permitirán identificar una serie de rupturas y de continuidades que, tras la independencia, afectaron a las formas de reproducción social del sur de Mozambique. Sin embargo, las rupturas fueron mucho más celebradas que las continuidades, con lo que "la herida colonial" se hizo más difícil de asumir (Pina Cabral, 2006: 209). Los planteamientos de Pina Cabral permiten argumentar que, en Mozambique, tanto el concepto de modernidad como el de tradición fueron esencializados por unas élites urbanas que competían por el control del Estado. El resultado, en ambos casos, fue que la legitimidad del Estado independiente se debilitó, pues la legitimidad es siempre el producto de un proceso de negociación constante por la hegemonía social.

Finalmente, en la tercera parte, propongo que la imposibilidad de actualizar la legitimidad de los ancianos en Massinga tiene relación con que las ruinas se hayan convertido en una referencia importante para ellos. Las ruinas de las casas de los mineros de antaño contrastan con la pobreza de las casas donde actualmente viven los ancianos y, en este sentido, permiten recordar lo que ya no existe (Sarró, 2009): un periodo de relativa abundancia donde los ancianos disponían de los recursos y la centralidad social necesaria para actualizar su legitimidad.

\section{Democracia y legitimidad en Mozambique: Los partidos, la nación y la tradición}

A mediados de 2006 me encontraba iniciando mi trabajo de campo etnográfico en el distrito de Massinga, donde quería investigar el arraigo y la legitimidad de las 
autoridades tradicionales treinta y un años después de proclamada la independencia de Mozambique (Farré, 2006, 2007; Kyed y Buur, 2006). Era consciente de que me enfrentaba a un tema sensible y delicado, pues durante la década anterior, marcada por una larga transición de un modelo de socialismo revolucionario a un modelo de democracia multipartidaria, la legitimidad de las autoridades tradicionales se había convertido en uno de los principales temas de discusión entre los dos grandes partidos políticos mozambiqueños: el Frente de Liberación de Mozambique (FRELIMO) y la Resistencia Nacional de Mozambique (RENAMO) ${ }^{3}$.

Durante la década de los noventa, el debate sobre la necesidad de restablecer las instituciones tradicionales estuvo presente en todo el continente africano (West \& Kloeck-Jenson, 1999; Perrot y Fauvelle-Aymar, 2003; Florêncio, 2005; Iniesta, 2007). En Mozambique, dos hechos de relevancia internacional marcaron la amplitud del debate y reforzaron su incidencia en la política mozambiqueña. Por un lado, la publicación del libro La Cause des Armes au Mozambique. Anthropologie d'une Guerre Civile (1990), del antropólogo francés Christian Geffray. Escrito por un investigador asociado a la izquierda intelectual y con una larga experiencia de campo en Mozambique, este libro generó una gran polémica entre los académicos que seguían la evolución política del país (O’Laughlin, 1992; Dinerman 1994, 2009; Cahen 2008). El discurso oficial del FRELIMO aseguraba que la guerra civil que empezó a finales de los setenta era, esencialmente, fruto de la desestabilización provocada por Rodhesia y Suráfrica, y que la RENAMO no era más que un grupo de bandidos y mercenarios a sueldo de aquellos regímenes racistas. El libro de Geffray proponía una lectura alternativa de la guerra en Mozambique: no toda la violencia venía de fuera, pues, independientemente de la injerencia extranjera, buena parte del apoyo interno que la RENAMO fue ganando a lo largo de la década de los ochenta era una respuesta a la violencia inherente al proyecto político del FRELIMO.

Por otro lado, por las mismas fechas en que se publicaba el libro de Geffray, el Ministerio de Administraciones Públicas puso en marcha un proyecto de investigación a escala nacional que estaba generosamente financiado por los Estados Unidos (West \& Kloeck-Jenson, 1999; Fry, 2000). Esta investigación se centraba precisamente en el papel de las autoridades tradicionales en la transición a un gobierno democrático, y en la necesaria revitalización de la sociedad civil mozambiqueña (Lundin y Machava, 1995, 1998). También en este caso la antropología fue prota-

3 El FRELIMO fue creado en 1962 como un Frente que aglutinó a diferentes partidos anticoloniales fundados fuera de Mozambique. En 1964 inició la lucha armada en el norte de Mozambique. Tras el 25 de Abril de 1974, fue reconocido por el Movimiento de las Fuerzas Armadas como el único representante del pueblo mozambiqueño al que traspasar el poder en el momento de la independencia, que tuvo lugar en 1975. En 1977 se convirtió en un partido marxista-leninista, asumiendo el papel de vanguardia revolucionaria. En 1989 abandonó formalmente su condición de Partido-Estado como paso previo a promulgar una Constitución liberal. La RENAMO, por su parte, fue creada por los servicios de inteligencia Rodesianos poco después de la indepencia de Mozambique con el fin de desestabilizar la revolución socialista en curso. Acogió a miembros de las antiguas fuerzas de seguridad coloniales, así como a disidentes del propio FRELIMO. Tras la independencia de Zimbabwe en 1980, la RENAMO pasó a rcibir el apoyo militar del régimen surafricano y, simultáneamente, se aprovechó de los errores del gobierno del FRELIMO para reclutar miembros en el interior de Mozambique. Hacia finales de los ochenta había conseguido extender sus acciones violentas en todo el país. Tras firmar los Acuerdos de Paz en 1992 la RENAMO se transformó en partido político, y se ha convertido en el gran adversario del FRELIMO en las elecciones. Desde las primeras elecciones de 1994 hasta el presente el FRELIMO ha continuado siendo el partido de gobierno, y la RENAMO el principal partido de la oposición. Desde el 2012 la tensión entre ellos vuelve a desarrollarse fuera de los cauces institucionales, con enfrentamientos militares localizados entre las fuerzas de seguridad y grupos armados de la Renamo (Macamo, 2014; Brito, 2014). 
gonista, pues la investigación de campo estaba liderada por la antropóloga brasileña Irãe Baptista Lundin. Sin embargo, mientras Geffray usaba la tradición para poner en el punto de mira el autoritarismo del FRELIMO y la violencia ejercida contra su propia población, la investigación liderada por Lundin era una iniciativa ministerial que ensayaba, a partir de las autoridades tradicionales, una adaptación ideológica a la nueva hegemonía neoliberal (West \& Kloeck-Jenson, 1999).

Además de estas dos iniciativas, muy vinculadas al contexto internacional posterior a la caída del muro de Berlín y al fin de la Guerra Fría, el debate sobre la tradición africana superó con creces el reducido ámbito de los académicos y los políticos para extenderse por diferentes foros: a lo largo de la década de los noventa, se convirtió en un tema recurrente de conversación en los medios de comunicación, en las iglesias, en las escuelas y hasta en los transportes públicos. La efervescencia del debate tenía algo de catarsis (Fry, 2000), y la multitud de opiniones dispares - y hasta rocambolescas - reflejaba una cierta liberación de los autoritarismos reinantes antes y después de la independencia. Como sucedía también en muchos otros países, la creatividad social parecía reclamar su oportunidad para ofrecer soluciones propias a los problemas africanos. En palabras de Ferrán Iniesta, "tras cincuenta años de modernidad plagiada, África retoma la palabra” (2007: 396).

\subsection{Salir de la burbuja urbana}

En 2006, hacía seis años que el gobierno mozambiqueño había aprobado el DecretoLey 15/2000, que establece las funciones de las autoridades comunitarias — designación que incluye tanto a los antiguos régulos, como a otros liderazgos locales que mostraran estar refrendadas por la población local, entre ellos los representantes del partido FRELIMO_- Mi intención era sondear el estado de opinión sobre la cuestión en un distrito concreto, así como evaluar el nivel de presencia institucional de tales autoridades en el día a día de la población rural. El distrito de Massinga es el más densamente poblado de la provincia de Inhambane, y la administración colonial había establecido tres regulados ${ }^{4}$ : Massinga, Zunguze y Mapera ${ }^{5}$.

Tras el Decreto-Ley 15/2000, los que habían sido representantes de estos tres regulados podrían volver a la luz pública, demostrar abiertamente el apoyo que recibían de la población, y ejercer de interlocutores con la administración distrital. Así, llegué a Massinga con voluntad de alejarme del ruido de los debates de la capital, y dedicar unos meses a poner en práctica la observación participante en Quême, lugar que recibía el nombre del que fue un reputado cabo de terras ${ }^{6}$ del antiguo regulado Zunguze: Francisco Quême Zunguze (Farré, 2008).

La información publicada sobre Massinga era escasa, pero existía una monografia agricola colonial (Almeida, 1959), realizada cuando el distrito entró a formar parte de la producción obligatoria de algodón7. Allí encontré dos fotos que hacían re-

\footnotetext{
[NdE] Regulado: territorio pequeño a cuyo cargo o poder estaba el régulo ( "señor", “jefe”..).

Durante el periodo colonial la circumscrição de Massinga era más grande que el actual distrito, pues incluía el actual distrito de Funhalouro. Esto no afecta a los tres regulados, que continúan en el distrito de Massinga, en la zona donde se concentra el mayor número de población: en las tierras fértiles alrededor de la villa de Massinga y a lo largo de la carretera nacional EN1.

6 Posición de la jerarquía administrativa colonial que estaba por debajo del régulo. Así, Quême era considerado por la administración uno de los cabos del régulo Zunguze.

7 Massinga fue uno de los últimos distritos donde se introdujo el cultivo forzado del algodón. Sobre el papel de
} 
ferencia al regulado Zunguze.. En la primera foto aparecía el régulo Zunguze vestido con su uniforme colonial, y acompañado de su secretario y consejeros. En la segunda aparecían dos casas, una de planta redonda y otra cuadrada, que, según se afirmaba en el pie de foto, pertenecían al Cabo Quême. Hice escanear e imprimir las dos fotos y me las llevé a Massinga, pues tenía la intuición de que serían de ayuda en algún momento de mi trabajo de campo.

Inicialmente, la primera foto no me resultó de gran ayuda, pues el régulo Zunguze residía a una cierta distancia de Quême, y muy poca gente supo reconocer con claridad a alguna de las seis personas que aparecían en aquella foto antigua. En cambio, la segunda foto sí que fue motivo de sorpresa, pues tanto jóvenes como ancianos reconocían las casas, y confirmaron que eran las de Francisco Quême, al que también llamaban de régulo en vez de cabo de terras ${ }^{8}$. Rápidamente reparé en este cambio de rango que le atribuían, y empecé a considerar si no estaría ante un primer indicio de que las categorías administrativas coloniales habían sido apropiadas por la población, hasta el punto de perdurar más allá del sistema que las creó.

Sólo meses más tarde intuí que se trataba de algo más. Visto en perspectiva histórica, me encontraba ante un verdadero doble salto mortal semántico: primero la administración colonial portuguesa creó una jerarquía local a partir de cómo imaginaba que se regían las sociedades africanas (Macagno, 2001) y, posteriormente, los africanos se apropiaron de una institución impuesta adaptándola en lo posible a los significados locales del ejercicio de la autoridad. Por un lado, el Estado colonial quería presentarse como si respetara las instituciones locales, como si simplemente sancionara las autoridades vigentes entre los africanos. Sin embargo, este simulacro sólo podía convencer a terceros - a todos aquellos a quien iba dirigido el discurso auto-justificativo del Imperio Portugués en África- pues para los propios africanos no había lugar a dudas: Cuando era investido alguien cuyo único mérito era la fidelidad a los portugueses, sabían que aquella persona no les representaba. En el caso del régulo Zunguze, por ejemplo, era sabido que el señor nombrado por los portugueses para tal cargo no era ni tan sólo de la familia Zunguze (Farré, 2008). ¿Quizás este hecho tenga algo que ver con que los residentes de Massinga llamaran también régulo al cabo de terras Francisco Quême Zunguze? Podría ser, pero lo cierto es que nadie me dio a entender tal cosa de forma suficientemente clara.

En cualquier caso, este doble juego de espejos entre lo impuesto y lo propio, mantenido durante las varias décadas que duró el Estado colonial, es la fuente principal de la presente confusión sobre la legitimidad tradicional. ¿Pertenecían los régulos a la simple inventiva del estado colonial, como afirman los defensores de la tesis de la invención de la tradición (Hobsbawn y Ranger, 1983; Vail, 1989)? ¿O más que una invención se produjo una suplantación de instituciones? Si se acepta el primer caso se asume que no habría posibilidad de un representante legítimo, pues la palabra "invención" da a entender que habría un vacío previo; mientras que si se acepta el segundo caso, se asume que existiría un suplantado, y se da a entender que, muy probablemente, era alguien más legítimo que su suplantador. Más allá de polémicas que tienden a convertirse en bizantinas, muy posiblemente invención y suplantación se dieron con frecuencia a lo largo y ancho del Mozambique colonial, pero, en cual-

los régulos en el cultivo forzado de algodón ver Isaacman (1987).

8 El 'cabo de terras ' es una posición administrativa que está por debajo del régulo. Cada régulo tenía varios cabos de terras por debajo. 
quier caso, la pregunta pertinente es: ¿Y de qué forma reaccionaron las diferentes sociedades africanas ante la invención o la suplantación del que había de ser su representante ante el Estado colonial? ¿Puede generalizarse como si todas lo hubieran hecho de la misma forma? ¿O hay que ir una a una para percibir el contexto preciso en que el Estado colonial se implantó entre aquella sección particular de la actual población mozambiqueña? ¿Y para elucidar cada caso bastaría la documentación escrita —eminentemente administrativa — o sería necesario también equilibrar esas fuentes con los recuerdos de quienes lo vivieron?

Estas son algunas de la muchas preguntas que continúan generando debate. Sin embargo, esta es sólo una parte de la complejidad con la que se lidiaba durante el debate de los años noventa. Existe otra parte que tiene que ver con la implantación del Estado independiente. La antipatía que sentía el FRELIMO por los régulos, a los que percibían como unos impostores que explotaban al pueblo por encargo del Estado colonial, dio una vuelta de tuerca más a un asunto ya de por sí complejo.

\subsection{Extirpar el colonialismo de la cabeza: la reeducación del régulo}

El mismo día que mostré aquellas fotos por primera vez fui conducido al lugar donde estaban las casas de Francisco Quême. El chico que me acompañaba me explicó que el antiguo régulo falleció bastante tiempo atrás — según pude calcular, en la primera mitad de los años noventa-, y que su residencia ya estaba en ruinas. Sin embargo, la casa de planta redonda, construida con paredes de cemento, todavía se mantenía en pie, siendo claramente reconocible por la decoración pintada en las paredes. Inicialmente no di mayor importancia a que aquellas casas fueran calificadas como "ruinas". Más tarde, a medida que me he ido familiarizando con la geografía de Quême, me he dado cuenta de que las ruinas son un elemento importante en el paisaje. Hay ruinas por doquier, superpuestas al presente ordenamiento del territorio, como si convivieran con el presente sin interferir en el curso de la vida cotidiana'.

Sin embargo, mas allá de la curiosidad de ver al natural unas casas que, en los años cincuenta, alguien consideró de suficiente interés para que su imagen fuera incluida en una monografía agrícola, en aquel primer momento, las fotos me sirvieron, sobretodo, para entrar en contacto con uno de los descendientes de Francisco Quême, que resultó vivir muy cerca de donde yo me alojaba. Se daba el caso que Alfredo ${ }^{10}$ había sido, además, el secretario de Francisco Quême y acabó convirtiéndose en uno de mis informantes más estables.

Alfredo me explicó en primera persona algo que ya había leído en algún lugar, aunque sin obtener nunca muchos detalles. Tras la independencia, aunque no se aplicó una política sistemática, algunos régulos fueron enviados a los campos de reeducación, y este fue el caso de Francisco Quême. Alfredo decidió acompañarlo, asumiendo así hasta el final su condición de secretario leal. Los campos de reeducación eran lugares de internamiento de todas aquellas personas consideradas comprometidas con el régimen colonial y, por tanto, sospechosas de disidencia política (Thomaz, 2008; Igreja, 2010). Además de los régulos, también fueron destinadas a la reeducación aquellas personas que ejemplificaban la corrupción causada por la vida urbana colonial, como las prostitutas, los especuladores, los alcohólicos, etc. Todos estos

Volveré a las ruinas más adelante, para referirme a ellas como un elemento de la memoria colectiva.

Siguiendo la convención en estos casos, omito su nombre real. 
colectivos debían ser reeducados para que volvieran a ser socialmente útiles, y poder reintegrarse a la revolución en marcha (Corrêa y Homem, 1977; Thomaz, 2008).

Para entender el origen intelectual de los campos de reeducación hay que retroceder al periodo de las guerras de liberación de las colonias portuguesas. Entre 1961, año en que empieza la guerra en Angola, y 1974, año en que un sector de las Fuerzas Armadas portuguesas toma el poder en Lisboa, los territorios africanos bajo soberanía portuguesa se vieron sometidos no sólo a la guerra y la represión policial, sino también a las intensas campañas de propaganda y acción psicológica del gobierno colonial para garantizar la fidelidad de la población, y sustraérsela a los movimientos de liberación (Monteiro, 2014). El objetivo de la acción psicológica se podría resumir en el lema ampliamente repetido de "Mozambique es Mozambique porque es Portugal", y que aseveraba que antes de la llegada de los portugueses aquellas tierras estaban habitadas por bandos que se mataban y se esclavizaban entre sí, y que si los portugueses se retirasen volvería sin duda la anarquía anterior. La acción psicológica fue acompañada, por una lado, de un reclutamiento y entrenamiento de soldados negros y, por el otro, de más inversiones, tanto por parte del Estado como del capital extranjero que aprovechó una mayor liberalización de la economía. También hubo cambios en el entramado jurídico-político del Imperio, que pasó a estar constituido por una serie de Estados cada uno con sus propias cámaras representativa y legislativa, y donde existían algunos diputados negros, con cuya presencia se pretendía justificar la condición multirracial de un Imperio que se definía como Lusotropical (Castelo, 1999).

Hubo algún intento de consolidar a los régulos como clase media rural, animándoles a crear cooperativas indígenas y propiciar así que un sector de población rural se sintiera atraída por la promesa de promoción social a corto y medio plazo. Uno de estos intentos fue precisamente en la provincia de Inhambane (Adam, 2006). También algunos assimilados ${ }^{11}$ fueron favorecidos en la asignación de tierras de regadío del Limpopo, aunque sus principales beneficiarios fueron familias portuguesas recién llegadas de la metrópoli (Castelo, 2012; Covane, 2001; Valá, 2003). Estos intentos fueron siempre aislados, pues nunca hubo una apuesta decidida por crear una clase media africana, entre otras cosas porque el ascenso de la potencial clase media negra se vio taponada por el envío masivo de portugueses de la metrópoli (Castelo, 2004, 2012). En el fondo, las reformas de los años 60 aguzaron el sentimiento de exclusión racial entre aquel sector de la población negra que quería aspirar a ser un ciudadano portugués normal (Covane, 2001; Adam, 2006).

El conjunto de todos estos estímulos económicos, a pesar de sus contradicciones, tuvieron un efecto suficiente para crear conflictos internos en el FRELIMO. Efectivamente, a los conflictos ideológicos y de estrategia propios de un Frente que aglutina a colectivos diversos (Opello, 1975; Cahen, 2010), había que sumar también las constantes sospechas de infiltración por parte de los servicios de inteligencia portugueses.

11 Assimilado era una categoría colonial que otorgaba la plena ciudadanía portuguesa a aquellas personas negras o mestizas que demostrasen llevar un modo de vida "civilizado": llevar una vida cristiana, dominar la lengua portuguesa, tener un empleo con el que sustentar a la familia y estar al día en los compromisos con el Estado, tales como impuestos, servicio militar, etc-. Los assimilados eran una minoría que se diferenciaba de los indigenas, categoría donde se encontraba la gran mayoría de la población negra (Honwana, 1989). En 1961, fueron derogadas la leyes que establecían las categorías sociales de indígena y assimilado, pero socialmente la diferencia siguió vigente. Sobre la condición de assimilado el libro más explícito son las Memórias de Raúl Honwana (2009). 
El punto culminante de todas las crisis abiertas en el seno del FRELIMO fue el asesinato de su primer presidente, Eduardo Mondlane, en Febrero de 1969. La muerte de Mondlane propició la toma de poder del sector militar, liderado por Samora Machel, y la expulsión del FRELIMO de miembros que hasta entonces ocupaban posiciones importantes, como Urias Simango y Lázaro Nkavandame, entre otros (Cahen, 2010). Aquel conflicto político tuvo continuidad con la guerra civil y continúa abierto en la actualidad, siendo un elemento más de la presente inestabilidad política en Mozambique (Brito, 2014).

En resumen, la década y media que va de 1961 a 1974 se caracterizó por una serie de cambios sociales acelerados y desordenados que se iban produciendo en simultáneo a la guerra de liberación, y que explican la profunda desconfianza con que los guerrilleros del FRELIMO acabaron percibiendo la sociedad mozambiqueña por la que luchaban. El ideal del "Hombre Nuevo", desarrollado durante la lucha armada, era una respuesta a esta percepción de degradación de la sociedad mozambiqueña. El Hombre Nuevo representaba al tipo de ciudadano mozambiqueño que era capaz de superar todos los prejuicios — de raza, de tribu, de religión - y todos los vicios — ambición, individualismo, promiscuidad sexual — inculcados por los portugueses. En breve, el Hombre Nuevo sería aquel mozambiqueño capaz de hacer un tabla rasa en su cabeza para convertirse en alguien movido sólo por la construcción de una sociedad mejor. Samora Machel, que fue el primer presidente de Mozambique, expresó así los riesgos de no conseguir materializar una sociedad de Hombres Nuevos:

"Incluso cuando hayamos destruido los sistemas de explotación, si no mantenemos la lucha contra la mentalidad que los determina, más pronto o más tarde, más lenta o más rápidamente, los sistemas renacerán de sus cenizas, fecundados por los valores negativos que fueron preservados en nuestro interior." ${ }^{2}$ (Apud Cabaço, 2001: 141).

Los campos de reeducación tienen mucho que ver con esta desconfianza hacia una sociedad alienada por el colonialismo, especialmente entre aquellos sectores que, tanto en el campo como en las ciudades, más habían recibido la presión propagandística y los incentivos económicos para mantenerse fieles al Imperio. Así, no es de extrañar que muchos de los que acabaron llenando los campos de reeducación fueran los régulos que controlaban las zonas rurales, como fue el caso de Francisco Quême.

A pesar de que los campos de reeducación fueron justificados como un instrumento pedagógico, lo cierto es que acabaron siendo el escenario de un verdadero ajuste de cuentas político contra los que, de alguna forma, se habían adaptado y beneficiado del régimen colonial, y también un lugar propicio para las venganzas personales, así como para todo tipo de mezquindades. En definitiva, el Estado independiente asumió, a su vez, la tarea de modelar una sociedad a su medida, y lo hizo con un celo superior al del Estado colonial. El testimonio de Alfredo, que acompañó a Francisco Quême a un campo de reeducación, refleja que la experiencia dejó cicatrices tanto físicas como morales, además de un profundo resentimiento: "Esto de la democracia es mentira. El poder no se escoge, el poder se arranca. A nosotros nos lo arrancaron".

12 Esta cita y las demás han sidos traducidos del portugués por el autor del artículo. 


\subsection{La revolución ante la diversidad rural y las modernidades alternativas}

En 1977, menos de dos años después de conseguida la independencia, el FRELIMO dejó de ser un Frente - en tanto que unión estratégica de diversos colectivos con un objetivo común - para pasar a ser un partido marxista-leninista, que se asumía como vanguardia revolucionaria de las masas de campesinos, trabajadores y soldados. En este nuevo contexto, los campos de reeducación no fueron la única ni la principal medida de transformación social. Hubo también una campaña de nacionalizaciones de empresas e inmuebles privados, y un proyecto de socialización del campo. Adolfo Yáñez Casal (1991) ha mostrado cómo la visión que el FRELIMO tenía del propio país era profundamente dualista, en donde el campo era la reserva de la pureza de un Mozambique que se mantenía intacto frente a los vicios que se acumulaban en la ciudad. Si la ciudad era un lugar moralmente degradado y hostil, el campo - una vez desactivados los régulos - era el aliado natural de los guerrilleros, como por otra parte se había demostrado, durante la guerra de liberación, en las llamadas zonas libertadas. En las zonas libertadas habría habido un sistema de producción comunitario donde soldados y campesinos, en comunión con los dirigentes, trabajaban en harmonía en pos de la formación de un Hombre Nuevo que posibilitaría la fundación de una sociedad mejor, una vez conseguida la independencia.

El historiador mozambiqueño João Paulo Borges Coelho $(2013,2015)$ ha descrito cómo el FRELIMO ha monopolizado la narrativa del pasado reciente (Bragança y Depelchin, 1986), mitificando el periodo de la lucha por la independencia y presentándolo como si de una fábula se tratara. Con el calificativo de fábula Borges Coelho quiere destacar que, desde la independencia, la historia de Mozambique se ha reducido a la reproducción de un relato simple, que contrapone personajes antagónicos, donde el bien - el FRELIMO - acaba triunfando sobre el mal —el colonialismo- y con el colofón de una lección moral que demuestra la razón del vencedor, y la suerte que han tenido los mozambiqueños de ser liberados por el FRELIMO.

En este sentido, la mitificación de las zona libertadas, que durante la guerra tuvo fines propagandísticos muy exitosos en la captación de apoyos y simpatías internacionales, fue el origen de la voluntad de extender el modelo a todo el país. Las aldeas comunales, donde se preveía concentrar a la población rural que hasta la fecha vivía dispersa, fue el eje del programa de socialización del campo. Se partía del presupuesto de que el campo necesitaba una acción contundente para salir del letargo colonial, un estímulo para salir de la subsistencia y empezar a modernizarse, y a producir excedentes mediante formas de trabajo colectivas, como supuestamente lo habían hecho las zonas libertadas. Correspondía al nuevo Partido-Estado movilizar a las masas rurales hacia la producción colectiva. En este sentido, la migración hacia las minas se veía como una pérdida de fuerza de trabajo que sólo beneficiaba a la acumulación capitalista del enemigo surafricano.

La realidad es que las dinámicas sociales y productivas del campo mozambiqueño eran bastante más complejas y modernas de lo que el FRELIMO estaba dispuesto a aceptar (O'Laughlin, 1981, 1996; First, 1983; Casal, 1988). Durante la década de los sesenta, el campo generaba excedentes para alimentar a las ciudades en expansión, y existía una dinámica consolidada de diferenciación social, especialmente entre aquellas familias rurales que tenían al menos un salario, y podían llamar a jornaleros para trabajar sus tierras en la época de más trabajo, y los que no tenían ningún salario y, por tanto, sólo podían conseguir dinero trabajando en las tierras de otros. 
Los más necesitados trabajaban incluso a cambio de comida, $\mathrm{u}$ otras formas de pago en especie. En este contexto, los régulos, ciertamente aprovechándose de los privilegios que les concedía el gobierno colonial, a veces ejercían de impulsores de la modernización de la economía. Los estudios de caso que tenemos sobre la evolución de los régulos en una zona concreta (João, 2000; Harrison, 1996, 1998; Florêncio, 2005; José, 2007; Farré, 2008), nos muestran a personas que en ningún caso estaban ancladas en el pasado por el peso de una tradición inamovible. Muy al contrario, los régulos eran un factor de cambio, pues se adaptaban para dar respuesta a los retos del momento, negociando las hegemonías sociales con los detentores del poder político y aprovechándose, en lo posible, de la ambigüedad de una posición social que les ofrecía a la vez privilegios "tradicionales" y oportunidades "modernas" (Moreira, 1960). La fortaleza de su liderazgo social se basaba en su dinamismo y creatividad social, capacidades que Harrison ha descrito como marketing legitimacy (Harrison, 1998).

En este sentido, muchos régulos eran representantes de modernidades alternativas a la modernidad urbana, donde los protagonistas eran los colonos europeos y sus descendientes, que se ocupaban principalmente en la burocracia del Estado y en la administración de las grandes empresas. Así, dependiendo del talante de cada régulo, y del tipo de relación personal que se establecía con él, la situación del habitante rural podía variar desde ser nefasta, a ser mucho más soportable que la situación en las ciudades, donde la exclusión racial a favor de los portugueses recién llegados de la metrópoli era mucho más sistemática y cotidiana.

Esta diversidad de situaciones que coexistían en el campo, es la que el FRELIMO no supo —o no quiso - apreciar. De hecho, la inquina contra los régulos no venía sólo por representar un poder del pasado, pseudo-tradicional en tanto que consolidado durante el colonialismo y a la sombra del colono, sino también porque representaban un proyecto de Mozambique independiente que era radicalmente opuesto al de la élite del FRELIMO. Es más, se puede argumentar que la deriva revolucionaria del FRELIMO fue consolidándose, y haciéndose cada vez mas apremiante a medida que las zonas libertadas iban creciendo, precisamente para desballestar la posibilidad de una independencia en que las posiciones de liderazgo social estuvieran ya ocupadas por aquellos que no fueron a luchar por la independencia (Opello, 1975). En otras palabras, para no regalar la independencia a aquellos compatriotas que no habían arriesgado nada por ella, el FRELIMO tendió cada vez más a unir la independencia con la revolución: había que asegurarse que el orden social colonial, y todas sus injusticias, no se mantendrían intactas una vez conseguida la independencia. Así, la fábula de la que habla Borges Coelho no servía sólo para establecer un relato oficial sobre el pasado reciente, necesario en todo nuevo Estado, sino que tenía la función añadida de recordar a los que no participaron en la lucha armada — es decir, a la inmensa mayoría de mozambiqueños - que no estaban entre los elegidos para gobernar.

Todo ello nos lleva a explicar que, cuando el FRELIMO tomó el poder en 1975, en vez de pactar con los sectores más dinámicos de la sociedad que existía, decidió que podía construir una sociedad nueva, desconfiando de todos. Sobrevaloró el recién conseguido control sobre el Estado y despreció a muchos sectores sociales que, a la vez ilusionados y sorprendidos con la independencia, habrían podido sumar sus esfuerzos para afianzar un Estado independiente. Los régulos estaban acostumbrados a renegociar hegemonías con los representantes del Estado, y una mayoría posible- 
mente lo habría hecho de buen grado con el nuevo Estado independiente, del que, como mozambiqueños, esperaban que fuera bastante más favorable que el Estado colonial portugués. Por el contrario, el FRELIMO los consideró feudales y obscurantistas, negándoles cualquier reconocimiento del dinamismo social y económico que representaban, y pasó a implantar un nuevo modelo en todo el país. No sólo los régulos, sino el grupo de ancianos que me dieron conversación en Massinga, formaban parte de este inmenso grupo de mozambiqueños no representados en la fábula triunfal: los que se sintieron excluidos por los nuevos dirigentes, y fueron y empujados a avergonzarse de su pasado si querían ser tenidos en cuenta (Igreja, 2008; Pina Cabral, 2006).

\subsection{Antiguos régulos y asimilados rememoran su pasado}

Gracias a mis visitas periódicas a Alfredo, el antiguo secretario del régulo Francisco Quême, fui teniendo la posibilidad de conversar con otros hombres ancianos que vivían en los alrededores, y con los que él mantenía una relación amistosa. Algunos de los más ancianos incluso me mostraron el documento que certificaba su condición de "assimilados", mientras otros mostraban un cierto recelo a ser llamados como tal, quizá por la connotación negativa que tuvo tras la independencia (Honwana, 1989). Con el tiempo me di cuenta de que la vida de muchos de estos ancianos compartía algunas características en común. La mayoría de ellos, tras una larga vida laboral en diferentes lugares de Mozambique y Suráfrica, había decidido regresar a su aldea natal para pasar allí los últimos años de su vida. Simultáneamente, muchos de ellos ocupaban, en tanto que ancianos, la posición de jefes rituales en las ceremonias y ofrendas familiares a los antepasados. La mayoría había estudiado en la escuela metodista de Cambine en la década de los sesenta ${ }^{13}$, aprovechando el aumento en la escolarización tras la supresión de la condición de indígena (Gasperini, 1984), y combinaba sin especial angustia su formación escolar cristiana con aquellas obligaciones familiares que, generalmente, se consideran más cercanas al espectro de lo tradicional.

Extrañados por mi afán en buscar los rastros de la tradición africana, algunos de ellos accedían con satisfacción a conversar conmigo. Además, comprobé con cierto alivio que hablaban en portugués con fluidez y, dado el reducidísimo uso de esta lengua en las zonas rurales de Mozambique, también con cierto orgullo. Mi presencia en Quême les permitía recordar tiempos pasados y, sobretodo, dejar constancia de sus desacuerdos con el rumbo que había tomado el país tras la independencia. En cierto modo, yo representaba una página en blanco sobre la que ellos podían exponer cuestiones de las que no siempre era fácil hablar.

Entre los que más traté, había un técnico de farmacia, un administrativo y un transportista. El primero, tras abandonar su puesto de funcionario en un hospital público, continuaba trabajando en una farmacia privada en el municipio de Massinga. Los otros dos no tenían ningún ingreso regular, y dependían de lo que cultivaban y de lo que, muy de vez en cuando, los hijos les enviaban desde la ciudad. Los principales temas de conversación de este grupo de hombres basculaban sobre dos grandes ejes. Por un lado hacían gala de un cierto cosmopolitismo regional: me hablaban de las ciudades donde habían vivido; de las empresas para las que habían trabajado; de sus

13 Para un análisis del papel de las iglesias protestantes en el sur de Mozambique ver Cruz e Silva (2001, 2004). 
salidas a países vecinos - Suráfrica, Zimbabue, Suazilandia— donde tenían familiares; de las iglesias a las que habían pertenecido; o de los misioneros y cooperantes ${ }^{14}$ con los que se habían cruzado durante las muchas peripecias de una vida que parecía haber estado en constante movimiento. Por otro, sin embargo, mostraban una gran tristeza y decepción por cómo habían discurrido sus vidas, y por las precarias expectativas sociales que sus hijos y nietos afrontaban en el presente (Farré, 2013). La guerra civil (1978-1992) ${ }^{15}$, si bien casi nunca era el foco de nuestras conversaciones, salía a relucir con frecuencia como trasfondo dramático ${ }^{16}$. En esos momentos, y a pesar de que todos se acordaban del racismo y las humillaciones que vivieron durante el colonialismo, se hacía explícita una vaga nostalgia por el tiempo colonial. "El colono gritaba mucho y pagaba poco. pero pagaba". Esta es una de las frases que oí en diversas ocasiones, sobretodo cuando se lamentaban de no recibir una pensión de jubilación, a pesar de que, según afirmaban algunos de ellos, por los años cotizados a lo largo de su vida les correspondería recibirla. Con razón o sin ella, entendían que la pensión escamoteada no era fruto de la ineficacia de un sistema administrativo precario, sino una decisión política tomada contra ellos.

Cierta vez pregunté porqué no pedían a sus hijos que vivían en Maputo que se preocuparan de preguntar sobre sus pensiones. La respuesta que obtuve del antiguo administrativo fue tajante: "Nuestros hijos no hablan portugués. Son incapaces de entrar en un ministerio a preguntar algo. Solo conocen el dumba-nengue ${ }^{17 \%}$. Esta respuesta ponía de relieve la brecha generacional de estos hombres con sus hijos y nietos. Unos habían crecido durante el boom económico y reformista de los sesenta, y los otros habían crecido durante la guerra civil. Unos habían accedido a las mejoras de acceso a la educación del tardo-colonialismo, y los otros sólo habían llegado a tiempo para sufrir el fiasco económico de la revolución socialista y la destrucción del país causada por la guerra. Unos habían conseguido abandonar las minas para trabajar en otros empleos, ya en Mozambique, que garantizaban una mejor calidad de vida, mientras los otros ni a los contratos de las minas pudieron acceder, como explicaré en el siguiente apartado. En consecuencia, la única opción laboral de estos últimos es engrosar las filas de los que vagan por las ciudades vendiendo todo tipo de buguigangas. Gran parte de ellos desconocen tanto la experiencia de una formación escolar completa como lo que es un contrato de trabajo, por explotador que sea (Farré, 2013).

Sin embargo, esta fractura generacional no tiene sólo repercusiones socio-económicas, pues en las tres provincias del sur de Mozambique (Maputo, Gaza e Inhambane), la importancia de la migración de los jóvenes a las minas representaba mucho más que la mayoría de los ingresos de las diferentes unidades domésticas. Tal como han subrayado diferentes autores (Norman, 2004; Vidal, 2014; Alconada, 2013) la

14 Así eran conocidos los militantes de izquierda que, tras la independencia, fueron a apoyar in situ el proyecto político de la Frelimo. En los años 1990 hubo otra ola de cooperantes ya más vinculados a las ONGs, que respondía a otro tipo de solidaridad internacional, supuestamente más técnica y menos ideológica, aunque coincidió con el auge del neoliberalismo.

15 Massinga se encuentra en el sur de Mozambique, y la guerra de liberación (1964-1974) nunca llegó a estar presente. En enero de 1974 el FRELIMO abrió un frente de guerra llegó a la zona centro (Sofala), y este hecho aceleró el plan del MFA para derrocar a la dictadura, que aconteció tres meses después (Cardoso, 2014).

16 Para un análisis de las memorias de las guerras ver Macamo (2006), Vakil, Monteiro y Machaqueiro (2011) y Bonate (2013)

17 Forma como se conocen los mercados informales de vendedores ambulantes. Dumba-nengue significa literalmente "confío en mis piernas". 
migración formaba parte del ciclo vital de los hombres hasta el punto de poder ser considerada un rito de paso de jóvenes a adultos, siendo el fin de la carrera minera un aspecto de especial importancia también en el paso de adultos a ancianos. En el siguiente apartado trataré de cómo las minas de oro moldearon la vida de toda la región durante la centuria que va desde su descubrimiento en 1880 hasta la independencia de Mozambique. Este contexto histórico es necesario para entender porqué esta ruptura generacional indicaba el fin de una época, poniendo en entredicho la continuidad del orden social establecido en las zonas rurales del sur de Mozambique.

\subsection{La migración como rito de paso y la reproducción social de las sociedades rurales}

El descubrimiento de minas de diamantes (1860) y de oro (1880) en la meseta de la actual República Surafricana reconfiguró toda la geopolítica del África austral. Las guerras de conquista colonial persiguieron el objetivo de asegurar el control de las minas, enfrentando a británicos y afrikáners entre sí, y a ambos con los reinos africanos en expansión. Una vez el imperio británico hubo conseguido su objetivo (1901), el reto pasó a ser que hubiera suficiente mano de obra para asegurar la explotación de las minas, pues la elevada demanda del sector minero entró a competir con la de las plantaciones de caña de azúcar y la agricultura (Etherington, 1979; Harries, 1994). Para dar respuesta a esta demanda se puso en marcha un sistema de contratación en origen de trabajadores procedentes de la India colonial británica. Sin embargo, la afluencia de hombres de toda la región austral dispuestos a trabajar en las minas hizo que, finalmente, los diferentes estados coloniales involucrados decidieran que la mano de obra africana era la única respuesta posible a la ingente demanda de trabajadores que exigían las minas.

Así, desde las últimas décadas del siglo XIX, se empezó a perfilar un sistema de contratación en origen que implicaba el acuerdo entre los diferentes estados coloniales de la región austral y las empresas mineras, que organizaron un sistema de contratación único para contener el aumento de los salarios (Covane, 1989). El estado colonial portugués aceptó que Mozambique se convirtiera en uno de los principales proveedores de mano de obra a las minas, y la única empresa contratadora de mineros expandió sus oficinas por el sur de Mozambique. Massinga, a unos $600 \mathrm{~km} \mathrm{al}$ norte de Maputo, fue el lugar más septentrional donde se encontraba una oficina de contratación (CEA, 1998).

Hasta la década de los setenta del siglo XX, la demanda de trabajo del sector minero se mantuvo constante, y las tres provincias del sur de Mozambique proporcionaban una media de 100.000 mineros al año (CEA, 1998; Covane, 2001). El sistema de trabajo asociado a las minas surafricanas ha sido objeto de una vasta literatura, entre otras cosas porque sus implicaciones sociales contribuyeron a que se fuera modelando el régimen del apartheid, que fue establecido oficialmente en 1948. Gran parte de esta literatura ha tenido por objeto la alta política de las múltiples negociaciones entre los estados involucrados y el capital interesado en invertir en las minas de oro, y con frecuencia los mineros quedaban reducidos a números y series estadísticas. Desde los años ochenta, varios historiadores sociales y antropólogos se han interesado en la agencia de los mineros africanos, y en las innovaciones culturales específicas de aquellas sociedades rurales que enviaban sistemáticamente a los jóvenes a trabajar en las minas (Harries, 1994; Norman, 
2004; Farré, 2013; Vidal, 2014; Alconada 2013). Así, aunque sometidos a una intensa explotación de su fuerza de trabajo, además de a un régimen segregacionista, los mineros tenían una agenda propia y, a lo largo de las generaciones, fueron desarrollando formas para llevarla a cabo. Con el tiempo, la economía de las zonas rurales del sur de Mozambique se fue volviendo cada vez más dependiente del salario de los mineros, y las principales ceremonias del ciclo vital, como el matrimonio o los funerales, se convirtieron en momentos que propiciaban una gran circulación de dinero.

Los jóvenes aportaban dinero de las minas, pero continuaban atados tanto a las jerarquías del linaje paterno como a las obligaciones de parentesco por alianza. Sólo a medida que sus propios hijos empezaban a emigrar - y a ganar dinero-, y sus propias hijas a casar - y a aportar compensaciones matrimoniales, en ganado o en dinero - un hombre podía decidirse a abandonar su condición de minero para permanecer en sus tierras. El minero retirado, convertido en anciano, pasaba a liderar in situ la propia dinámica familiar, y a participar en la política local centrada en los régulos y los cabos de terras (Webster, 2009). Por consiguiente, para dejar de ser joven había que dejar de ser minero, pero sólo se podía dejar de ser minero si otros más jóvenes alimentaban la demanda de mano de obra en las minas. Dejar de ser minero abría las puertas a la condición de anciano.

Es en este contexto que varios autores han destacado como la migración a las minas llegó a poder considerarse un rito de paso masculino, pues se convirtió en el proceso habitual por el que un joven conseguía casarse y formar una unidad doméstica propia, convirtiéndose así en adulto (Norman 2004; Alconada 2013). William Norman (2004) ha señalado que los ritos que se realizan a la ida y al regreso de las minas podrían ser equiparables con los ritos de salida y de reintegración del modelo clásico de rito de paso propuesto por Van Gennep (2008 [1909]). Por su parte, Ruth First (1983) propuso catalogar a los migrantes mozambiqueños como proletarianpeasants, precisamente para reflejar que, en su caso, el trabajo asalariado no representaba una ruptura con los vínculos sociales propios de las sociedades rurales. Esta continuidad no quería decir que no existiera un proceso de transformación profunda de dichas sociedades rurales. Simplemente las formas mediante las que se transformaban no respondían a lo esperado según la teoría clásica de la modernización social. Además, esta tendencia era reforzada por el hecho que los estados coloniales surafricano y mozambiqueño tenían interés en mantener a las sociedades rurales dentro del campo semántico de lo tradicional, pues eso les permitía justificar la decisión de negarles los derechos de ciudadanía, a cambio de concederles que se siguieran rigiendo por la costumbre ${ }^{18}$. Mamdani (1996) ha descrito este modelo institucional como de despotismo descentralizado.

Lo importante es que los ancianos, en su mayoría antiguos mineros retirados, continuaban controlando gran parte del dinero y de los presentes que traían los jóvenes para casarse. Los régulos, por su parte, en su doble función de representante local del Estado y ancianos, también recibían un impuesto/presente de cada minero retornado (Isaacman, 1987; Covane, 2001). El anciano que había trabajado de administrativo, por ejemplo, me dijo que Francisco Queme dispensaba los regalos de sus familiares, pero no de los otros trabajadores que regresaban a casa después de haber estado trabajando fuera del regulado. Actualmente, ofrecer un pequeño billete

18 El ámbito de lo tradicional fue tipificado en inglés como customary rights, y en portugués usos e costumes. 
a la autoridad comunitaria siempre que se requiere de su acción continúa siendo una práctica habitual.

En las dos últimas décadas del periodo colonial, la reformas referidas generaron más puestos de trabajo para mozambiqueños asimilados, o con un cierto nivel de escolarización, y la pequeña elite rural africana dejó de estar formada simplemente por régulos y su círculo de colaboradores, para incluir a algún funcionario de la administración, o a empleados de empresas privadas, como era el caso de algunos de los ancianos que me dieron conversación. A pesar de estas mejoras, la economía rural continuaba dependiendo del dinero de los salarios en las minas. Este sistema de reproducción social alrededor de la migración laboral a las minas contaba con más de un siglo de vida e innovación social cuando, a mediados de los años setenta, dejó de funcionar abruptamente.

La caída del Imperio Portugués y, con él, de todo el sistema de alianzas geopolíticas del que formaba parte, remodelaron el sistema de contratación de trabajadores para las minas (First, 1983). Tras la independencia, Mozambique pasó a ser enemigo de Suráfrica, y las minas surafricanas dejaron de contratar a todos los jóvenes mozambiqueños que aspiraban a iniciar su carrera como mineros. Sólo continuaron siendo admitidos los que ya tenían experiencia. Con esta decisión se cortaba el ciclo que iba a permitir a los mineros con experiencia retirarse de las minas para convertirse en ancianos rurales. Hubo una generación de mineros que dejó de tener las espaldas cubiertas por una nueva generación de mineros que los reemplazaba (Norman, 2004; Farré, 2013).

Para entender la soledad y la melancolía de los ancianos que actualmente viven en Massinga hay que tener en cuenta que, aunque ellos no fueran mineros, su generación pertenece a la de los primeros ancianos que sufrieron las consecuencias de aquel corte: también en su caso se encontraron que, una vez retirados de sus respectivos trabajos, ya nadie más trajo dinero con la periodicidad y las cantidades a la que la sociedad rural se había acostumbrado. Ciertamente, los jóvenes continuaron emigrando a Suráfrica, pero ya hemos visto que la mayoría pasó a trabajar de forma informal (dumba nengue), ya fuera en el comercio ambulante (Grest y Nhambi, 2009), ya en las ocupaciones estacionales del turismo o de la agricultura (Vidal, 2014). Sin contratos, y sin capacidad de prever lo que iban a conseguir ahorrar - si es que conseguían ahorrar-, dejaron de regresar a sus zonas rurales de origen con la previsibilidad y la frecuencia de antaño (Norman, 2004; Vidal, 2014). Dejaron también de poder planificar cuándo y con quién casarse (Farré, 2015a).

Este proceso de ruptura generacional coincidió en el tiempo con la guerra civil, que todavía agravó más la pobreza sobrevenida a las zonas rurales. Tras la guerra, vino la transición a la democracia, que no trajo de vuelta el dinero de los salarios perdidos, ni tampoco a los jóvenes emigrados. Y sin jóvenes ni salarios, la condición de anciano perdía mucho de su sentido. Las mujeres solteras, por su parte, dejaron de esperar en casa a casarse con un minero, y se pusieron en marcha hacia los suburbios de las ciudades, donde había más posibilidad de integrarse en el creciente comercio informal (Waterhouse y Vijfhuizen, 2001), y también menos control social para encarar una vida más autónoma (Farré, 2015a, 2015b).

\subsection{La transición a la democracia y el auge de la recuperación de la tradición}

A inicios de los noventa el Estado mozambiqueño estaba desahuciado. Tras el fracaso de la revolución y el ocaso del Hombre Nuevo, el FRELIMO no tenía pro- 
yecto político más allá de mantenerse en el poder. La RENAMO, por su parte, se había ganado a pulso tal reputación de brutalidad (Hall, 1990; Seibert, 2008) que le era complicado presentarse como partido de gobierno. Por consiguiente, ambos necesitaban presentarse a las primeras elecciones — programadas para 1994- de forma renovada.

En este contexto, y dada la repercusión internacional que tuvieron los debates africanos sobre la recuperación de la tradición, los dos principales partidos políticos mozambiqueños creyeron que las autoridades tradicionales podían servir para estructurar un discurso político ganador. Sobretodo la RENAMO, que quería presentarse como el gran defensor de la democracia, presentó a las autoridades tradicionales como si fueran una gran esperanza para la instauración de la democracia en Mozambique. Pero también argumentaba en el mismo sentido una parte del FRELIMO, representado por el ministro de Administraciones Estatales que apoyó la investigación mencionada al inicio (West y Kloeck-Jenson, 1999; Kyed y Buur, 2006; Kyed, Buur y Silva, 2007). El segundo intento de forjar un relato del pasado nacional estaba en pleno apogeo, y el concepto de autoridad tradicional se convirtió en una de las principales piedras de toque para contrastar los diferentes modelos de sociedad propuestos por cada partido, así como sus diferentes formas de reivindicar la democracia y el progreso (Farré, 2006).

Mozambique comenzó a vivir una situación un tanto paradójica: mientras en la capital del país una parte creciente de la intelectualidad urbana suspiraba por reencontrarse con una tradición idealizada, los supuestos representantes de esta legitimidad tradicional con los que yo he podido conversar en Massinga suspiraban, a su vez, por un orden social que los conectaba a las minas, a los salarios y al Estado en su versión colonial. Es cierto que los ritos y ceremonias de formato tradicional continuaban regulando la vida social. Pero no lo era menos que, para ellos, la tradición no tenía sentido desligada de los salarios que sustentaban tanto aquellas ceremonias sociales como, sobretodo, la autoridad de los ancianos que las ejecutaban y las presidían. La división entre modernidad y tradición, pues, podía alimentar debates en la capital, pero no convencía a los ancianos de Massinga. Lo que ellos esperaban de los representantes del Estado no era que, tras varias décadas de desprecio, vinieran ahora a ponerles los galones de la tradición africana. Más bien demandaban una solución que reparara el empobrecimiento y la violencia a la que habían sido sometidos tras la independencia.

La independencia había coincidido con el fin de un sistema de reproducción social, y los nuevos dirigentes se habían apresado a vanagloriarse por el fin de la explotación de los mozambiqueños en las minas, pero no habían sido capaces de reponerlo por uno mejor o, por lo menos, por uno igual de eficaz. Por otro lado, los ancianos no ponían en duda que hubo una injerencia externa para desestabilizar Mozambique, pero insistían en que era igual de cierto que tanto los campos de reeducación como la fallida socialización del campo eran errores que no se podían imputar a los regímenes racistas de antaño.

En definitiva, de un forma mucho más confusa, fragmentada y malhumorada, los ancianos de Massinga me conducían, nuevamente, al que fue el argumento principal del ya mencionado libro de Christian Geffray (1990), que tuvo su momento de gloria en el contexto de los debates que marcaron la negociaciones por la paz entre el FRELIMO y la RENAMO. Es más, la perspectiva de los ancianos de Massinga ponía en evidencia un aspecto del libro que, en el contexto de los debates de los años 
noventa, tan focalizados en la tradición, me había pasado desapercibido. A pesar de usar la tradición como argumento, la intención principal de Geffray posiblemente no se dirigía tanto a resaltar la legitimidad de las autoridades tradicionales per se, sino más bien a subrayar el autoritarismo y la falta de legitimidad del propio Estado mozambiqueño independiente; a mostrar las continuidades existentes entre el estado colonial y el independiente, sobretodo en lo que se refiere a la actitud desconfiada del Estado ante la mayoría de la población.

\section{Formas de pensar el pasado y el self tras la ruptura colonial}

Hasta aquí he descrito cómo los dos principales relatos de un pasado nacional han chocado con la indiferencia, el escepticismo o el profundo desacuerdo de un grupo de ancianos de Massinga. Por otra parte, aunque mi interés se ha centrado en un grupo muy específico de ancianos, he procurado mostrar que las relaciones difíciles con el pasado - y especialmente con el pasado oficialmente establecido - es algo que no afecta sólo a este grupo de ancianos, sino que es una característica bastante más general de la sociedad mozambiqueña, como queda también reflejado en los trabajos de $\mathrm{M}^{\mathrm{a}}$ Anne Pitcher (2006), Macamo (2006), Thomaz (2008), Michel Cahen (2010), Igreja (2010), Cabaço (2011), Borges Coelho (2013) Bonate (2013) y Souto (2013, 2015). En esta segunda parte, me propongo esbozar algunas pistas que expliquen las dificultades que tiene una gran mayoría de mozambiqueños para pensar su pasado individual y colectivo.

El antropólogo portugués João de Pina Cabral ha dedicado algunos de sus artículos a Mozambique, y especialmente a las complejas formas en que cambio y continuidad se entrelazan en los recuerdos y en las identidades de muchos mozambiqueños (Pina Cabral 2000, 2002, 2004, 2006). Pina Cabral, como él mismo explica en varios de sus artículos, pasó buena parte de su infancia y juventud en Mozambique, y este hecho no es inocuo en sus reflexiones. De hecho, la mayoría de sus artículos sobre Mozambique están escritos entre 1999 y 2006, periodo en que, gracias a diferentes invitaciones académicas, tuvo la posibilidad de regresar a Mozambique tras más de dos décadas de su partida. Este regreso le proporcionó la ocasión de reflexionar sobre cómo nos relacionamos individual y colectivamente con el pasado. Aquí me interesaré especialmente por dos de sus artículos, en donde desarrolla algunos conceptos de interés para el tema que nos ocupa, especialmente porque permiten abordar la cuestión de la legitimidad desde una perspectiva diferente a como hasta ahora se ha debatido en Mozambique.

En uno de los últimos artículos de su serie sobre Mozambique, Pina Cabral (2006) utiliza los conceptos de preteridad y de solidaridades primarias para explicar la construcción del self individual y colectivo. Las solidaridades primarias son creadas desde la infancia y tienen una importancia especial en la formación de la persona social. En periodos de alteraciones políticas rápidas, como los que vivió Mozambique antes y sobretodo después de la independencia, las solidaridades primarias pueden ser reelaboradas, pero no sin esfuerzo, y siempre hasta un cierto punto, pues a nadie se le puede exigir que se olvide completamente de sí mismo. Pina Cabral expone algunos ejemplos de entre las personas con las que trató en sus visitas a Mozambique. Un antiguo asimilado que consiguió rehacer su vida como mozambiqueño, con lo cual tuvo que reprimir ciertos hábitos de pensar que pasaron a estar muy mal vistos tras 
la independencia, pero que seguía manteniendo una cierta estética "nacionalista modernista vinculada a una cultura histórica lusófila" (Cabral, 2006: 209). Otro ejemplo es el de un amigo que, en una conversación informal sobre los tiempos pasados, pasó a quejarse vehementemente sobre el desgaste de haber tenido ya tres vidas: una como portugués, otra como socialista y otra como hombre de negocios (Cabral 2006: 211-212). En ambos casos, los ejemplos propuestos nos muestran a personas que, a pesar de las dificultades sufridas, consiguieron rehacer sus vidas y encontrar un lugar social en cada nuevo contexto. Por el contrario, los ancianos con los que yo hablé no lo consiguieron, y parte de su malestar viene de la consciencia profunda de que, a pesar de sus intentos, en algún momento perdieron el tren que los hubiera llevado a una vejez mejor que la que tienen.

El concepto de preteridad (pastness) también se refiere a la formación del self, de la propia identidad, pero tiene un alcance más colectivo. Se refiere a un conjunto de referencias del pasado en común, y la capacidad que tienen los individuos que han compartido ese pasado de identificarse a través de esas referencias. Aquí los ejemplos de Pina Cabral incluyen más su propia experiencia como portugués que vivió el periodo tardocolonial en Mozambique y que, por ello, comparte una serie de referencias de su pasado más con los mozambiqueños que, por ejemplo, con sus colegas académicos que siempre vivieron en la metrópoli. A pesar de que su proximidad social con sus colegas académicos es mucho más elevada, sus recuerdos sobre el jardín de Dona Berta (2002), sobre un cierto tipo de escuela colonial-salazarista, o sobre la impresión que causaba ver regresar a los mineros de Suráfrica vestidos de gala y cargados de regalos, sólo puede compartirla con los mozambiqueños que también lo vivieron. Aunque los mozambiqueños y él lo recuerden de formas diferentes, porque sus respectivas situaciones sociales eran diferentes, el simple hecho de haberlo vivido les da a ambos la posibilidad de reconocerse en esas referencias, aunque sea desde la discrepancia.

Tanto con las solidaridades primarias como con la preteridad, Pina Cabral quiere subrayar la importancia de las continuidades. En otras palabras, indica la imposibilidad de llevar a cabo rupturas radicales con el pasado personal y colectivo, y advierte sobre el malestar y la violencia que se genera cuando alguien se ve forzado a hacerlo. De hecho, Pina Cabral relaciona los elevados niveles de violencia vividos durante la guerra civil mozambiqueña con el resentimiento agudo de mucha gente que, tras la independencia, se sintió forzada a desacreditarse a sí mismo de la noche a la mañana, a renegar de sus solidaridades primarias, para poder convertirse en un buen mozambiqueño.

Es curioso que Samora Machel, cuando hablaba de la posibilidad de que, a pesar del éxito de haber conseguido la independencia, el sistema colonial puede "renacer de sus cenizas, fecundado por los valores negativos que fueron preservados en nuestro interior” (Cabaço, 2001:141), posiblemente intuía la fuerza de las continuidades a las que Pina Cabral se refiere. Claro que Samora hablaba de esta posibilidad como un riesgo que hacía falta evitar a toda costa, y el Hombre Nuevo era precisamente el antídoto para evitarlo. Pina Cabral, por el contrario, hace una lectura diferente, más sofisticada, de la formación de las identidades sociales y de los cambios que se pueden llevar a cabo. Los cambios pueden llegar a ser muy importantes, pero requieren de un proceso, de una digestión. Así, más que amputar lo que nos disgusta de nuestro pasado, primero hay que reconocerlo como parte de nosotros: 


\begin{abstract}
"En suma, el acto de la independencia no implica únicamente el rechazo de un opresor por parte de una población subalternizada. Esta descripción es profundamente reduccionista. Implica también enfrentarse al hecho que el opresor se ha vuelto parte del oprimido. El sujeto postcolonial encuentra dentro de sí mismo el reflejo distorsionado de la dominación imperial. En el caso de los asimilados, esta condición es más patente, pero se verifica, en diferentes niveles, en todos los miembros de la población anteriormente subalternizada." (Pina Cabral, 2006: 209)
\end{abstract}

Este proceso de cambio es un proceso creativo, donde se elaboran nuevos significados a partir de lo que ya existe. Esta innovación está siempre condicionada por unas relaciones de poder, por una hegemonías que, para serlo, están siempre en proceso de legitimación. Y este es precisamente el tema del segundo artículo de Pina Cabral (2000) que quiero destacar aquí. En este caso el autor hace una reflexión sobre los conceptos de liminalidad, margen y hegemonía en el que se remite a los trabajos de Arnold Van Gennep y de Victor Turner. Este es un artículo de análisis teórico sobre el proceso de formación de hegemonías sociales, mediante la tensión constante entre la estructura y la communitas, la convivencia entre innovación y continuidad. Pero lo que hace a este artículo todavía más interesante es que Pina Cabral hace explícito la contemporaneidad de Van Gennep con Henri Junod, el misionero suizo que aplicó la idea de rito de paso a las sociedades del sur de Mozambique.

Junod relaciona el rito de paso entre los tsonga con el cambio de residencia preceptivo tras la muerte de un hombre adulto. La unidad doméstica alargada, el muti, en tanto que complejo residencial que se compone de varios edificios dentro de una empalizada redonda, estaría ritualmente identificada con el padre de familia. Una vez muerto éste, los miembros de la familia que vivían bajo su autoridad deben distribuirse en otras unidades domésticas de parientes próximos del difunto (generalmente sus hermanos). Con la muerte de un hombre adulto, pues, el muti que él construyó - tanto física como socialmente - para albergar a sus dependientes, pasa a convertirse en ruina (Cabral 2000: 866-867). Por lo tanto, la construcción y el abandono de casas estaba relacionado en tiempos de Junod — primeras décadas del siglo XX - con la reproducción de las unidades sociales básicas: el muti. A partir de esta constatación, Pina Cabral hace un seguimiento de las diferentes recepciones que la obra de Van Gennep tuvo en las diferentes escuelas de la antropología social británica, desde Radcliffe-Brown — que mantuvo polémicas con Junod sobre parentesco (Farré, 2015)—, hasta Max Gluckman y Victor Turner.

Pero lo que me interesa destacar aquí es que la vida de los ancianos de Massinga, así como las ruinas de casas que allí existen, como en todo el sur de Mozambique (Pombo, 2015), permitirían ilustrar precisamente el proceso de cambio y continuidad que Pina Cabral detalla en la teoría. Tanto el Estado colonial como la migración laboral acabaron transformando las sociedades rurales del sur de Mozambique. Sin embargo existen algunas continuidades, y la descripción de Junod nos indica que las casas y las ruinas ejemplifican, en alguna medida, estas continuidades. Las migración a las minas permitió a los jóvenes casarse y construir nuevas casas, con plantas diferentes y materiales más duraderos - lo que contribuye a que las ruinas persistan más-. La autoridad de los ancianos, por su parte, encontró un espacio para reproducirse bajo la administración portuguesa, y los régulos fueron el resultado de ese proceso continuo de renegociación de hegemonías a varios niveles: entre ancianos y jóvenes, entre Estado colonial y ancianos, entre Estado colonial portugués y capital 
minero. La legitimidad de los régulos, cuando existía, no era por ser tradicionales - como aseguraba la retórica colonial — sino porque la habían conseguido actualizar en un contexto social concreto, y así habrían de seguir haciéndolo si querían conservarla.

Con la independencia, el FRELIMO consiguió el poder del Estado, y con él la posibilidad de negociar desde una posición hegemónica. En vez de eso, desestimó cualquier negociación y, en consecuencia, el Estado independiente ha ido perdiendo cada vez más base social, con el resultado de que su legitimidad ha ido menguando. El intento de recuperar la legitimidad apelando a la tradición, como intentaron ambos partidos políticos que protagonizaron la transición a la democracia, no dio resultado porque redundaba en el mismo error. La legitimidad no es tradicional ni moderna, la legitimidad es siempre el producto de una negociación desigual entre la hegemonía y sus subordinados, que implica la aceptación de una serie de continuidades y de rupturas, cuyos efectos futuros son casi siempre imprevisibles.

\section{Las ruinas y la legitimidad en Massinga}

El problema principal de los ancianos con los que he podido conversar en Massinga se puede plantear de la forma siguiente: en un pasado que ellos todavía conocieron, regresar definitivamente a la zona rural de origen tras haber completado una serie de contratos en las minas era pasar a ocupar la centralidad social (Webster, 2009). Allí tenían a sus esposas y descendientes; allí acabarían de construir su propia casa con el dinero ahorrado en las minas; allí pasarían a recibir, a su vez, a los jóvenes que habían empezado a ocupar su lugar en las minas; y finalmente allí podían relacionarse con el estado colonial — algo distante - a través del régulo y sus cabos de terras - que lo hacían más próximo-. La consecución de esta centralidad social suponía haber superado con éxito un largo periodo de trabajo en las minas, y permitía el control del dinero que continuaba circulando en Massinga gracias a los salarios de los jóvenes que continuaban en las minas.

Sin embargo, ninguna generación de mineros reprodujo exactamente lo que hicieron sus padres, pues la industria minera experimentaba cambios sustanciales a cada década que pasaba. No se debe olvidar que los siglos XIX y XX fueron muy convulsos - guerras africanas y conquistas coloniales, guerras mundiales, crisis financieras, independencias y revoluciones_-, y la región minera del África Austral no fue ajena a ninguno de los efectos de aquellas convulsiones, entre otras cosas porque buena parte del oro que mantenía el sistema financiero internacional se extraía de las minas surafricanas (First, 1983). Por tanto, las diferentes generaciones de mineros vivieron formas diferentes de trabajar en las minas, pero también es cierto que el modelo de reproducción social se mantenía en lo esencial: generación tras generación, el salario de las minas alimentaba la economía rural, y las formas de poder local dependían, en buena medida, del control sobre la circulación de ese dinero a través de ceremonias tradicionales. Así, un dinero eminentemente moderno se convertía en tradicional una vez llegaba a Massinga, y la legitimidad tradicional obtenía sabia nueva gracias a la economía moderna. La tensión entre cambio y continuidad, tal como refiere Pina Cabral, exigía la actualización del pasado en cada generación, y la legitimidad existente era el producto de la renegociación de las hegemonías sociales entre jóvenes y ancianos. 
En los años setenta, esta forma de reproducción social empezó a desaparecer, debido a la drástica reducción del número de mozambiqueños jóvenes contratados por las minas. Sin embargo, la superposición de la independencia, la revolución y la guerra civil hizo que nadie fuera plenamente consciente de ello hasta que las cosas se calmaron, ya entrados los años noventa, cuando la paz dejó que el polvo reposara de nuevo sobre la superficie del suelo.

Al contrario de lo que muchos esperaban, el fin de la guerra y el establecimiento de la democracia no hizo recomenzar las idas y venidas de los jóvenes mineros (Norman, 2004). Sin nadie que regresara con dinero y regalos, las chicas solteras se fueron percatando de que ya nadie iba a construir casas nuevas, para formar nuevas unidades domésticas —muti - donde ellas podrían ser esposas (Farré, 2015a, 2015b). Cualquier excusa empezó a servir para marcharse del campo y dirigirse a las zonas periféricas de las ciudades, donde se generaba un nuevo dinamismo de lo informal. Los ancianos fueron perdiendo así la centralidad social que los matrimonios de los jóvenes les otorgaban.

Con el correr del tiempo, los ancianos se encontraron que la zona rural donde estaban ya no era el centro de nada, y ya nadie tenía interés en negociar nada con ellos: ni el Estado — que hacía tiempo que había defenestrado a los régulos como sus representantes - ni los jóvenes - que ya no regresaban de forma previsible con el fin de cada contrato, pues ya no había contratos-. Curiosamente, esta soledad coincidió con el auge de una forma de esencializar la tradición por parte de ciertas élites urbanas en pugna por el poder del Estado, lo que todavía causó más perplejidad en la referida generación de ancianos.

Los ancianos, pues, se han ido quedando cada vez más aislados, habitando una zona cada vez más periférica y remota, donde el dinero no circula, y donde permanecen las ruinas de un periodo de relativa abundancia que no ha de regresar: casas viejas que recuerdan un pasado que ellos no han podido actualizar. En la medida que la migración a las minas acabó convirtiéndose en el elemento central de la reproducción social en el sur de Mozambique, la construcción de casas era uno de los principales signos de éxito de los mineros retornados. Hoy los jóvenes ya no regresan de las minas con dinero para casarse y construir nuevas casas y, en consecuencia, los ancianos han perdido la posibilidad de actualizar su antigua legitimidad.

Las ruinas se han convertido en un elemento doblemente importante para los ancianos de Massinga. Por un lado, las casas que cada generación construía, siguiendo las modas y materiales del momento, representaban tanto la compleja gama de continuidades con el pasado como las expectativas de cambios y mejoras que exige cada nueva generación de jóvenes. Esta tensión social era la fuente de toda legitimidad, renegociada por cada nueva generación de ancianos que, tras dejar las minas, asumía las riendas de la sociedad rural, y de las ceremonias que la pautaban. Y es precisamente esta tensión negociadora entre generaciones, lo que se ha intentado negar desde la independencia: bien celebrando la ruptura con el Estado colonial y esencializando una modernidad construida desde cero; bien queriendo recuperar una tradición precolonial que se imaginaba como el receptáculo de una legitimidad no contaminada por el colonialismo. Pero la legitimidad tradicional se reproduce precisamente por su condición ambigua dentro de dos formas de reproducción social simultáneas. A pesar del hábito colonial de pensar dos tipos de sociedad diferenciada, las autoridades tradicionales las unían para conseguir legitimarse ante sus poblacio- 
nes y ante el Estado. Linaje y dinero, casas y régulos, matrimonios y migración, Estado y ceremonias tradicionales, todos son ingredientes necesarios de la permanente actualización del pasado, y de las renovadas expectativas de futuro. Es precisamente esta capacidad de seguir renovando la legitimidad a pesar de circunstancias siempre cambiantes lo que podría ser considerado como formando parte de una tradición africana que se mantiene, en parte, autónoma del Estado.

Por otro lado, las ruinas también les hacen recordar lo mucho que han perdido desde la independencia: las casas que tendrían que haber substituido a las actuales ruínas simplemente no existen. Las ruinas son, pues, la preteridad (Cabral, 2006) que comparten durante sus encuentros bajo la sombra de las palmeras, a los que yo tuve la suerte de poder asistir. Pero la principal razón de su melancolía no es tanto la nostalgia, sino que ya nunca la compartirán con ninguno de sus nietos, porque sus hijos y nueras ya no residen cerca de ellos. No hay legitimidad posible cuando tanto el Estado como los propios descendientes han dejado de venir a negociarla contigo. La legitimidad tradicional que concierne a sus hijos e hijas se estará negociando en otros lugares más concurridos, donde la tensión entre ruptura y continuidad se planteará bajo nuevas formas tan ambiguas como innovadoras, pero ellos ya han quedado al margen.

\section{Referencias bibilográficas}

Adam, Yussuf (2006). Cooperativazação na agricultura e relações de produção em Moçambique. Maputo: Promédia.

Alconada, Álvaro (2013). Madjonjoni. Sociedad, cultura y migración en el sur de Mozambique. Tesis doctoral. Departamento de Antropología. Universidad Complutense de Madrid.

Almeida, Armando Antunes de (1959). Monografia Agrícola de Massinga (Posto Sede). Lisboa: Junta de Investigaçðes do Ultramar.

Bonate, Liazzat (2013). "Muslim memories of the liberation war in Cabo Delgado". Kronos, 39 (1): 230-256.

Borges Coelho, João Paulo (2013). "Politics and contemporary history in Mozambique. A set of epistemological notes". Kronos, 39 (1): 10-19.

— 2015. "Abrir a fábula: Questoes da polítiica do passadoem Moçambique". Revista Crítica de Ciências Sociais, 106: 153-166. doi: 10.4000/rccs.5926.

Bragança, Aquino de; Depelchin, Jacques (1986). "Da idelaização de Frelimo à comprensão da história de Moçambique", Estudos Moçambicanos, 5/6: 29-52.

Brito, Luis de (2014). "Uma reflexão sobre o desafio da paz em Moçambique”. En Sérgio Chichava, Luis de Brito et al. (Orgs.), Desafios para Moçambique 2014, Maputo: IESE, 23-39.

Cabaço, José Luis (2001). "O homen novo. Breve itinerário de um projecto". en António Sopa (Ed.). Samora. Homen do Povo, Maputo: Maguezo Editores, 137-146.

- 2011. "Violência atmosférica e violências subjetivas. Uma experiência pessoal". Revista Brasileira de Ciências Sociais, 76: 213-218. http://dx.doi.org/10.1590/S010269092011000200013

Cahen, Michel (2008). "A la recherche de la défaite. Notes sur une certaine historiographie de la 'révolution' et de la 'contre-révolution' au Mozambique et sans doute ailleurs". Politique Africaine, 112: 161-181. doi : 10.3917/polaf.112.0161

- 2010. "Moçambique: o fim da história... única. Trajectórias dos anti-colonialismos em Moçambique”. Africana Studia, 15:195-240. 
Cardoso, Ribeiro (2014). O Fim do Império. Memória de um soldado protuguês. Lisboa: Caminho.

Casal, Adolfo Yáñez (1988). “A crise de Produção Familiar e as Aldeias Comunais em Moçambique”, Revista Internacional de Estudos Africanos, 8-9: 157-191.

- 1991. "Discurso socialista e camponeses africanos: legitimação política-ideológica da socialização rural em Moçambique (FRELIMO 1965-1984)”, Revista Internacional de Estudos Africanos, 14-15: 35-76.

Castelo, Cláudia (1999). 'O modo português de estar no mundo'. O luso-tropicalismo e a ideologia colonial portuguesa (1933-1961). Porto: Afrontamento.

— 2004. «'Um segundo Brazil ou um terceiro Portugal’, políticas de colonização branca da África Portuguesa». Travessias, 4/5: 155-180.

— 2012. "'O branco do mato de Lisboa': a colonização agrícola dirigida e os seus fantasmas”. En Claudia Castelo, Omar Ribeiro Thomaz et al. (Orgs.) Os Outros da colonização. Ensaios sobre o colonialismo tardío em Moçambique. Lisboa: ICS, 27-50.

Corrêa, Sonia; Homem, Eduardo (1977). Moçambique. Primeiras Machambas. Rio de Janeiro: Margem Editora.

Covane, Luis António (1989). As relações económicas entre Moçambique e a África dos Sul 1850-1964. Acordos e regulamentos principais, Maputo: Arquivo Histórico de Moçambique, Estudos 6.

- 2001. O Trabalho Migratório e a Agricultura no Sul de Moçambique (1920-1992). Maputo: Promédia.

Cruz e Silva, Teresa (2001). Igrejas Protestantes e consciência política no sul de Moçambique: O Caso da Missão Suiça (1930-1974). Maputo: Promédia.

- 2004. "Identidade religiosa e construçao da democracia em Moçambique: o Caso da Igreja Metodista Unida de Moçambique" Travessias 4/5, 223-235.

Dinerman, Alice (1994). "In search of Mozambique: The Imaginings of Christian Geffray in La Cause des Armes a Mozambique. Antropologie d'un Guerre Civile». Journal of Southern African Studies, 20(4): 569-586. http://dx.doi.org/10.1080/03057079408708422

- 2009. «Regarding Totalities and escape hatches in Mozambican Politics and Mozambican Studies». Politique Africaine, 113: 187-210. doi : 10.3917/polaf.113.0187

Etherington, Norman (1979). "Labour supply and the Genesis of the South African Confederation in the 1870s". The Journal of African History, 20 (2): 235-253.

Farré, Albert (2006). "El debate sobre las autoridades llamadas tradicionales en Mozambique". Nova África, 18: 75-85.

- 2007. "Mozambique. De territorios, culturas y personas", en F. Iniesta (Ed.), La Frontera Ambigua. Tradición y Democracia en África. Barcelona: Bellaterra, 359-380.

— 2008. "Vínculos de sangue e estruturas de papel: ritos e território na história de Quême (Inhambane)". Análise Social, XLIII (2ª): 393-418.

- 2013. "A broken Link. Two generations in a rural household in Massinga district, southern Mozambique.", Anthropology Southern Africa, 36 (3 \& 4): 124-129. http://dx.doi.org/ 10.1080/02580144.2013.10887036

- 2015a. "Women as Mediators in Post-war Mozambique: Pushing Lobolo from Price to Propriety", in Kaith Hart (Ed.), Economy for and against democracy, New York: Berghahm Books, 83-102.

- 2015b. "Las Mujeres y el Mito de la Agricultura de Subsistencia. De la exportación de alimentos a la dependencia alimentaria en el sur de Mozambique", Cadernos de Estudos Africanos, 29: 31-58. 
First, Ruth (1983). Black gold: the Mozambican miner, proletarian and peasant. Brighton: The Harvester Press Limited.

Florêncio, Fernando (2005). Ao encontro dos Mambos. Autoridades Tradicionais vaNdau e Estado em Moçambique. Lisboa: ICS.

Fry, Peter (2000). "Cultures of differences. The Aftermath of Portuguese and British Colonial Policy in Southern Africa". Social Anthropology, 8 (2):117-143. doi: 10.1111/j.14698676.2000.tb00125.

Gasperini, Lavinia (1984). «Direction culturelle, éducation et développement au Mozambique». Revue Tiers Monde, XXV n. 97: 189-204.

Geffray, Christian (1990). La Cause des Armes au Mozambique. Anthropologie d'une Guerre Civile. Paris: Karthala.

Hall, Margaret (1990). “The Mozambican National Resistence Movement (Renamo). A study in the destruction of an African country". Africa, 60(1): 39-68.

Harries, Patrick (1994). Work, Culture and Identiy: Migrant Labourers in Mozambique and South Africa, c. 1860-1910. Johannesburgh: Heinemann-Witswatersrand University Press.

Harrison, Graham (1996). "Democracy in Mozambique: The Significance of Multy-Party Elections", Review of African Political Economy, 67: 19-35. doi:10.1080/03056249608704175

- 1998. «Marketing Legitimacy in Rural Mozambique: The case of Mecufi District, Northern Mozambique», The Journal of Modern African Studies, 36 (4): 569-591.

Hobsbawn, E., Ranger, T. (Eds.) (1983). The invention of tradition. Cambridge: CUP.

Honwana, Raúl Bernardo (1989). Memórias. Lisboa: ASA.

Igreja, Victor (2008). "Memories as weapons: The politics of peace and silence in post-civil war Mozambique". Journal of Southern African Studies, 34 (3): 539-56. http://dx.doi. org/10.1080/03057070802259720

- 2010. «Frelimo's Political Ruling through violence and Memory in Postcolonial Mozambique». Journal of Southern African Studies, 36 (4): 781-799. http://dx.doi.org/ $10.1080 / 03057070.2010 .527636$

Iniesta, Ferrán (2007). "Epílogo. Encrucijadas en el Bosque. Diálogos con el leopardo", en F. Iniesta (Ed.), La Frontera Ambigua. Tradición y Democracia en África. Barcelona: Bellaterra, 393-398.

Isaacman, Allen (1987). "Régulos, diferenciaçao social e protesto rural. O regime de cultivo forçado de algodão em Moçambique". Revista Internacional de Estudos Africanos, 6-7: 37-82.

João, Benedito Brito (2000). Abdul Kamal e a História de Chiúre nos Séculos XIX e XX. Um Estudo sobre as Chefias Tradicionais, as Redes Islâmicas e a Colonização Portuguesa, Maputo: Arquivo Histórico de Moçambique.

José, André Cristiano (2007). “Autoridades ardilosas e democracia em Moçámbique”. En H. Kyed, L. Buur. T. da Silva (Orgs.), O reconhecimento pelo Estado das Autoridades Locais e da participação pública. Experiências, obstáculos e possibilidades em Moçambique. Maputo: CFJJ, 63-87.

Kyed, Helena Maria; Buur, Lars (2006). "New Sites of Citizenship: Recognition of Traditional Authority and Group-Based Citizenship in Mozambique". Journal of Southern African Studies, 32 (3): 563-581.

Kyed, H., Buur, L. Silva, T. (2007). «Introduction: perspectives on Decemtralization and Public Participation». En H. Kyed, L. Buur. T. da Silva (Orgs.), O reconhecimento pelo Estado das Autoridades Locais e da participação pública. Experiências, obstáculos e possibilidades em Moçambique. Maputo: CFJJ., 7-35. 
Lundini, I., Machava, F., (Eds.) (1995). Autoridade e Poder Tradicional. Vol. I. Maputo: Ministério de Administração Estatal. Núcleo de Desenvolvimento Administrativo.

- 1998. Autoridade e Poder Tradicional. Vol. II. Maputo: Ministério de Administração Estatal. Núcleo de Desenvolvimento Administrativo.

Macagno, Lorenzo (2001). “O discurso colonnial e a fabricação dos usos e costumes. António Enes e a 'geração do 95'”, Peter Fry (Org.), Moçambique. Ensaios, Rio: UFRJ, 61-90.

Macamo, Elísio (2006). “Accounting for disaster: Memories of War in Mozambique”. Africa Spectrum, 41 (2): 199-219.

- 2014. "Cultura política e cidadania em Moçambique. Uma relação conflituosa". En: Sérgio Chichava, Luis de Brito et al. (Orgs.), Desafios para Moçambique 2014. Maputo: IESE, 41-60.

Mamdami, Mahmood (1996). Citizen and Subject.Contemporary Africa and the Legacy of Late Colonialism, Princeton: Princeton University Press.

Massó Guijarro, Ester (2007). “El día de los Héroes en Katima Mulilo (2006): ¿Reconocer para ganar? Legitimidad y memoria histórica en la franja de Caprivi". Studia Africana, 18: 139-149.

Monteiro, Manuel Amaro (2014). Eu viví a queda do Império. Lisboa: Letras Itinerantes.

Moreira, Adriano (1960). "As élites das provincias portuguesas de indigenato (Guiné, Angola, Moçambique)”. En: Adriano Moreira, Ensaios, Lisboa: Junta de Investigações do Ultramar. 35-62.

Nhambi, Simão; Grest, Jeremy (2009). "Mobility, Migration and Trade: Interactive Flows Between Durban and Southern Mozambique", en: Luis de Brito; Carlos Castel-Branco et al. (Coords.), Southern Africa and Challenges for Mozambique, Maputo: IESE, 5987.

Norman, William O. (2004). Living on the Frontline: Politics, Migration and Transfrontier Conservation in the Mozambican Villages of the Mozambique-South Africa Borderland. Tesis doctoral. Antropologia. London School of Economics and Political Science.

O’Laughlin, Bridget (1981). “A questão Agrária em Moçambique”, Estudos Moçambicanos, 3: 9-32.

- 1992. "A base social da Guerra em Moçambique”. Estudos Moçambicanos, 10: 107-142.

- 1996. "Through a divided glass: Dualism, Class and The Agrarian Question in Mozambique", Journal of Peasant Studies 23 (4): 1-39.

Opello, Walter (1975). «Pluralism and elite conflict in an Independence Movement: Frelimo in the 1960s», Journal of Southern African Studies, 2(1): 66-82.

Perrot, Claude-Hélène; Fauvelle-Aymar, François-Xavier (2003). Le retour des rois. Les autorités traditionelles et l'état en Afrique contemporaine. Paris: Karthala.

Pina Cabral, João (2000). «A difusao do liminar: margens, hegemonias e contradiçoes» Análise Social, vol. XXXIV (153): 865-892.

— 2002. "Dona Berta's Garden: reaching across the colonial boundary" Etnográfica, VI (1): 77-91.

— 2004. "Cisma e continuidade em Moçambique" en Clara Carvalho y João de Pina Cabral, A persitência da História, Lisboa: ICS, 375-392.

— 2006. "Rios e estaçoes: solidariedades primárias e preteridade em Moçambique" en Manuel Villaverde Cabral, José Luis García e Helena Jerónimo (Orgs.) Razão, Tempo e Tcnologia: Estudos em homenagem a Hermínio Martins, Lisboa: ICS, 197-225.

Pitcher, Mary Anne (2006). "Forgetting from above and Memory from Below: Strategies of Legitimation and Struggle in Postsocialist Mozambique". Africa. Journal of the International African Institute, 76 (1): 88-112. 
Pombo, Pedro (2015). «Narrating Ruins. Landscapes of belonging and the remains of history in a southern Mozambican district», paper presented at the International Conference A Luta Continua. 50 years Later held at Wits University (Johanesburg) on the 4th-5th November 2015.

Sarró, Ramón (2009). The politics of religious change on the upper Guinea coast. Iconoclasm done and undone. Edinburgh: Edinburgh University Press.

Seibert, Gerhard (2008). "Alteraciones de violencia y poder en el Mozambique postcolonial”, en J. Abbink, M. de Bruijn y K. Van Walraven (Eds.), A propósito de resistir. Repensar la insurgencia en África. Barcelona: Oozebap, 355-387.

Souto, Amélia Neves de (2013). "Memory and identity in the history of Frelimo: some research themes". Kronos, 39 (1), 280-296.

- 2015. "Moçambique. Descolonização e transição para a independência: herança e memória", en F. Rosas, M. Machaqueiro y P. Aires Oliveira (Eds.), O adeus ao Império. 40 anos de descolonização portuguesa. Lisboa: Vega, 141-156.

Thomaz, Omar Riberio (2008). “'Escravos sem dono'. A experiência social dos campos de trabalho em Moçambique no período socialista”. Revista de Antropologia, 51 (1): 177214.

Vakil, Abdoolkarim; Monteiro, Fernando A. y Machaqueiro, Mário A. (2011). Moçambique: Memória Falada do Islão e da Guerra. Lisboa: Almedina.

Vail, Leroy (Ed.) (1989). The creation of tribalism in Southern Africa. Berkeley: University of California Press.

Valá, Salim Cripton (2003). A problemática da Posse da Terra na Região Agrária de Chókwè (1954-1995). Maputo: Promédia.

Van Gennep, Arnold (2008) [1909]. Los ritos de paso. Madrid: Alianza.

Vidal, Dominique (2014). Migrants du Mozambique dans le Johannesburg de l'aprèsapartheid. Travail, frontières, altérité. Paris: Karthala-Ifas.

Wewster, David (2009). A Sociedade Chope. Indivíduo e aliança no sul de Moçambique. Lisboa: ICS.

West, H., Kloeck-Jenson, S. (1999). "Betwixt and between: 'traditional authority' and democratic decentralization in postwar Mozambique". African Affairs, 98: 455-484. 